\title{
Influência das variáveis de processo do hidrociclone para tratamento de argilas esmectitícas
}

\section{(Effects of hydrocyclone process variables for treating bentonite clays)}

\author{
A. J. A. Gama', J. M. R. Figueirêdo ${ }^{1}$, J. M. Cartaxo' ${ }^{2}$ M. A. Gama ${ }^{2}$, G. A. Neves ${ }^{2}$, H. C. Ferreira ${ }^{2}$ \\ ${ }^{1}$ Programa de Pós-Graduação em Ciência e Engenharia de Materiais, ${ }^{2}$ UAEMa, CCT, UFCG, \\ R. Aprígio Veloso 882, Campina Grande, PB 58429-900 \\ agama@reitoria.ufcg.edu.br,jullymrc@gmail.com,julianamelo25@gmail.com,mgama@reitoria.ufcg.edu.br, \\ gelmires.neves@ufcg.edu.br,heber.ferreira@ufcg.edu.br
}

\begin{abstract}
Resumo
Recentemente foram descobertos novos depósitos de argilas esmectíticas no estado da Paraíba, localizados nos municípios de Cubati, Olivedos, Sossego e Pedra Lavrada. Estudos preliminares evidenciaram que estes depósitos apresentam na sua composição mineralógica elevados teores de minerais acessórios como mica, sílica livre e carbonatos. A presença desses minerais restringe em muito o uso industrial, sendo necessários estudos sobre tratamento dessas argilas para redução desses contaminantes. Estudos recentes mostraram que o uso do hidrociclone é uma alternativa viável por requerer um baixo investimento de instalação e manutenção, sendo amplamente utilizado na indústria mineral. Este trabalho teve como objetivo estudar as variáveis de processo do hidrociclone para tratamento de argilas esmectíticas de um novo depósito do estado da Paraíba. A argila esmectítica antes e após hidrociclonagem foi caracterizada física, química e mineralogicamente, pelas seguintes técnicas: análise granulométrica por difração a laser, difração de raios X, análise química por fluorescência de raios X e análise térmica. A argila foi dispersa na concentração de $4 \%$ e com defloculante hexametafosfato de sódio sob agitação por $24 \mathrm{~h}$. As variáveis de processo utilizadas no hidrociclone foram: pressão, aberturas do vortex e apex. Os resultados conduziram a um aumento do concentrado da fração argila, redução do diâmetro médio equivalente das partículas e redução dos minerais acessórios.
\end{abstract}

Palavras-chave: variáveis de processo, hidrociclone, argilas esmectitícas.

Abstract

Recently, new deposits of smectite clays were discovered in the state of Paraiba, located in the districts of Cubati, Olivedos, Sossego and Pedra Lavrada. Preliminary studies have shown that these deposits contain high contents of accessory minerals in their mineralogical composition such as mica, free silica and carbonates. The presence of these minerals results in very limited industrial use, and studies on treatment of these clays is necessary to reduce these contaminants. Recent studies have also shown that the use of a hydrocyclone would be a viable alternative because it requires low investment in installation and maintenance and is being widely used in the mineral industry. The aim of this work was to study the hydrocyclone process variables for treating smectite clays of a new deposit in the state of Paraiba. The smectite clay was physically, chemically and mineralogically characterized before and after hydrocycloning by the following techniques: particle size analysis by laser diffraction, X-ray diffraction, chemical analysis by X-ray fuorescence and thermal analysis. The clay was dispersed at a concentration of $4 \%$ and used with sodium hexametaphosphate dispersant under stirring for $24 \mathrm{~h}$. The process variables used in hydrocyclone were pressure along with vortex and apex openings. The results led to an increase in clay fraction concentration, reducing the average equivalent particle size diameter and the accessory minerals.

Keywords: process variables, hydrocyclone, smectite clays.

\section{INTRODUÇÃO}

Atualmente, pode-se definir bentonita como sendo uma rocha composta principalmente por um argilomineral esmectítico (montmorilonita), formado pela desvitrificação e subsequente alteração química de material vítreo, oriundo da decomposição de rochas vulcânicas, de preferência ácidas, depositadas em lagos ou rios de baixa turbulência [1-3]. As argilas esmectitícas são materiais constituídos por um, ou mais, argilominerais esmectíticos e alguns minerais acessórios (principalmente quartzo, cristobalita, micas, feldspatos e alguns outros argilominerais como a caulinita). Tem partículas de tamanhos que variam de $2 \mu \mathrm{m}$ a tamanhos bastante pequenos como $0,1 \mu \mathrm{m}$ de diâmetro, com tamanho médio de $0,5 \mu \mathrm{m}$ e formato de placas ou lâminas hexagonais de perfil irregular [4-6]. O estado da Paraíba possui grandes reservas de argilas esmectíticas com destaque as do município de Boa Vista; atualmente essas reservas encontram-se em fase de exaustão das variedades mais nobres em virtude da exploração desordenada, 
resultando como consequência sério prejuízo para sua aplicação industrial. Recentemente foram descobertas novas ocorrências de argilas esmectíticas nos municípios de Cubati, Olivedos e Sossego, PB; atualmente os estudos sobre esses depósitos encontram-se em fase preliminar, com destaque os trabalhos [7-9]. Nesses trabalhos, concluiu-se que as argilas desses municípios apresentam em sua composição mineralógica elevados teores de minerais acessórios como mica, quartzo, calcário além do argilomineral caulinita. A presença desses minerais acessórios restringe em muito o uso industrial, sendo necessário um estudo sobre tratamento dessas argilas para redução desses minerais, o que aponta para o uso do hidrociclone.

No tratamento de minérios o hidrociclone é a classe mais importante de equipamentos destinados à separação de suspensões líquido-líquido ou sólido-líquido. A separação se dá por sedimentação centrífuga, em que as partículas em suspensão são submetidas a um campo centrífugo que provoca sua separação do fluido $[10,11]$. Esse tipo de equipamento é simples de operar e requer baixo investimento de instalação e manutenção, sendo amplamente utilizado na indústria mineral, química, têxteis e petroquímica. Pesquisas sobre tratamentos de minerais utilizando hidrociclone foram intensificadas nos últimos anos com destaque para o trabalho [12], no qual foi estudado o desempenho de um hidrociclone, sendo avaliado os parâmetros vazão, pressão, concentração de alimentação e eficiência do sistema. Os resultados evidenciaram que a eficiência final é independente da concentração da suspensão de sólidos. Em [13] realizou-se uma pesquisa com duas argilas do município de Boa Vista - PB, utilizando um hidrociclone para a purificação dessas argilas naturais em escala piloto. Os resultados demonstraram que este sistema é eficaz para retirada das frações grosseiras, principalmente com diâmetros superiores à faixa de 2 a $5 \mu \mathrm{m}$. Em [14] realizouse um estudo com bentonitas sódicas, coletadas na região da Turquia, que foram submetidas a uma série de testes por hidrociclone de estágios múltiplos para avaliar a eficiência de separação e produzir bentonitas purificadas. Concluiuse que o melhoramento do tratamento consiste de duas hidrociclonagens: a primeira com um diâmetro maior do vortex $(14,3 \mathrm{~mm})$, seguida pela menor $(8,0 \mathrm{~mm})$, obtendo produtos de qualidade desejada. Em [15] foi estudado e avaliado o desempenho de um hidrociclone utilizando partículas sólidas, oriundas dos processos erosivos e do assoreamento de rios e barragens. Os resultados mostraram que a perda de carga no hidrociclone avaliado aumentou potencialmente com o acréscimo da vazão de alimentação e que o equipamento avaliado foi eficiente na remoção de partículas sólidas, notadamente para água contendo areia, sendo recomendado seu uso em sistemas de irrigação. Em $[16,17]$ foi relatado que a eficiência da classificação do hidrociclone é limitada por finos, que são descarregados em conjunto com a água do underflow. Em [18] foi validado um modelo de simulação que descreve o fluxo no hidrociclone. Os resultados da simulação foram comparados com dados experimentais da literatura. Em [19] foram realizados estudos experimentais sobre a influência do vortex no desempenho de hidrociclone, sendo dimensionado um hidrociclone com boa eficiência de separação com baixo consumo energético. Em [20] foram realizadas caracterizações e obtidas argilas beneficiadas através das técnicas de peneiramento e hidroclonagem com bentonitas recentemente descobertas no estado da Paraíba para diversas aplicações industriais. Em [21] foi verificada a influência da pressão no processo de purificação por hidrociclonagem em bentonitas das novas ocorrências do estado da Paraíba; os resultados mostraram que o processo de purificação em baixas pressões não é eficiente. Em [22] foram desenvolvidos estudos com o objetivo de concentrar a fração argila de misturas de argilas bentoníticas pouco nobres do estado da Paraíba por meio do processo de hidrociclonagem, e posterior secagem por spray dryer. Os resultados evidenciaram a eficiência das operações de hidrociclonagem e da secagem por spray dryer das misturas com notável melhoria das propriedades reológicas.

Este trabalho teve como objetivo estudar influência das variáveis de processo do hidrociclone para tratamento de argilas esmectíticas dos novos depósitos do estado da Paraíba.

\section{MATERIAIS E MÉTODOS}

Foi utilizado neste trabalho uma amostra de argila bentonítica proveniente dos novos depósitos do estado da Paraíba, designada como AM1, localizada na fazenda Campos Novos no município de Cubati-PB. Amostra foi beneficiada através de desagregação em moinho de bolas, em seguida classificada em peneira ABNT n $200(0,074 \mathrm{~mm})$. Para tratamento dessa argila foi utilizado o hidrociclone RWK 42L fabricado pela Netzsch AWK, Alemanha, com capacidade de separação de partículas com diâmetro de 2 a $5 \mu \mathrm{m}$. A Fig. 1 ilustra o esquema técnico do hidrociclone.

As dispersões foram preparadas da seguinte forma: misturou-se $1200 \mathrm{~g}$ de argila (seca em estufa a $60{ }^{\circ} \mathrm{C}$ para retirada parcial de umidade) em um volume de $30 \mathrm{~L}$ de água destilada com hexametafosfato de sódio na proporção de $45,7 \mathrm{~g} / \mathrm{L}$, obtendo-se uma dispersão de argila em água em concentração de $4 \%$ em massa, mantida sob agitação à velocidade de $2000 \mathrm{rpm}$ por um período de $24 \mathrm{~h}$ em temperatura ambiente. Após esse período, a dispersão foi bombeada para centrifugação no hidrociclone, com pressão variando de 3,0 a 4,0 bar (300 a $400 \mathrm{kPa}$ ), abertura do vortex variando de 3 a $5 \mathrm{~mm}$ e abertura do vortex de 5,0,5,5 ou $6,0 \mathrm{~mm}$.

A caracterização física, química e mineralógica da amostra in natura e após hidrociclonagem foi realizada pelos seguintes métodos: análise granulométrica por difração de laser (AG, CILAS 1064); análise química por fluorescência de raios X (EDX, Shimadzu 720); difração de raios X (DRX, Shimadzu XRD 6000), com radiação Ka do $\mathrm{Cu}(40 \mathrm{kV} / 30 \mathrm{~mA})$ e velocidade do goniômetro de $2 \%$ min e passo de $0,02^{\circ}$, com faixa de varredura de $5^{\circ}$ a $40^{\circ}$. A análise termogravimétrica (ATG) e análise térmica diferencial 


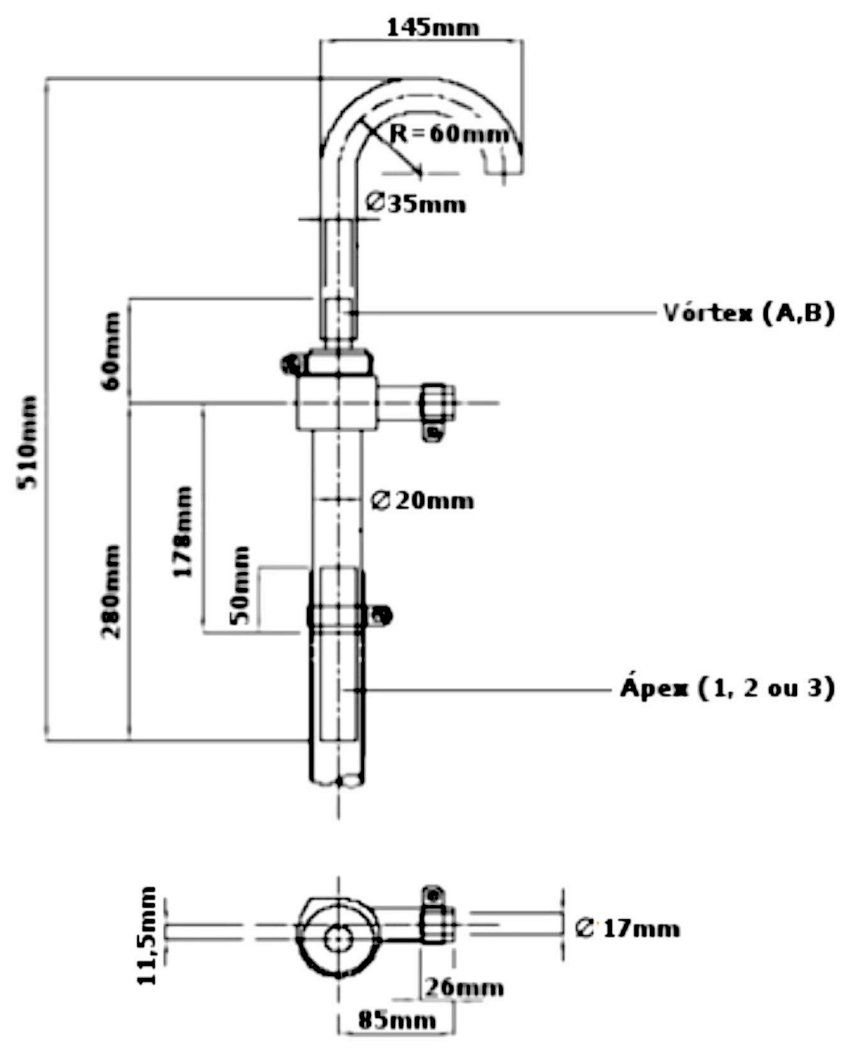

Figura 1: Representação esquemática do hidrociclone RWK 42L. [Figure 1: Schematic representation of the RWK 42L hydrocyclone.]

(ATD) foram realizadas em um sistema de análises térmicas (BP RB-3000), com taxa de aquecimento de $12,5^{\circ} \mathrm{C} / \mathrm{min}$, temperatura máxima para ambos de $1000{ }^{\circ} \mathrm{C}$ e o padrão utilizado na ATD foi o óxido de alumínio $\left(\mathrm{Al}_{2} \mathrm{O}_{3}\right)$ calcinado a $1200{ }^{\circ} \mathrm{C}$.

\section{RESULTADOS E DISCUSSÃO}

Na Fig. 2 estão ilustradas as curvas de DRX da amostra AM1 in natura com e sem etilenoglicol. Observou-se que a amostra estudada apresentou a seguinte composição mineralógica: argilomineral esmectítico (JCPDS 29-1497) caracterizado pelas distâncias interplanares basais de $15,66,4,43,3,59$ e $2,55 \AA$, que foi confirmado pelo uso do etilenoglicol que aumentou a distância interplanar de 15,66 para 16,66 Å; presença do argilomineral caulinítico (JCPDS 14-0164) caracterizado pela distância interplanar basal de 7,13 $\AA$; presença de minerais acessórios, como: quartzo (JCPDS 46-1045), caracterizado pelas distâncias interplanares basais de 4,22, 3,34, 1,82 e 1,66 A; feldspato (JCPDS 13-0294) caracterizado pela distância interplanar basal de 3,22 Å; e calcita (JCPDS 05-0586) caracterizado pela distância interplanar basal de 3,01 Å. Esses resultados evidenciaram que a argila desse novo depósito apresentou semiquantitativamente elevados teores de minerais acessórios, como constatados nos valores da sua composição química. Esses resultados foram similares aos resultados preliminares estudados por [9].

Na Fig. 3 estão ilustradas as curvas de ATD e ATG para a

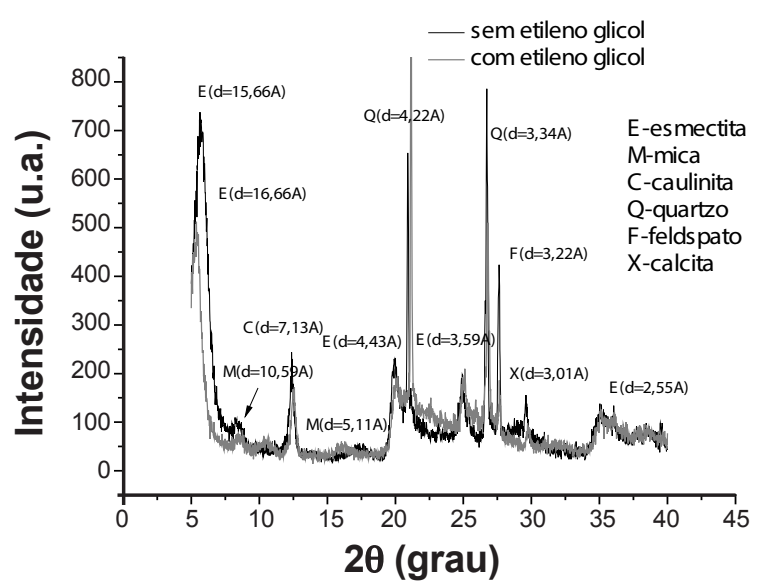

Figura 2: Difratogramas de raios X para a amostra AM1 in natura com e sem etilenoglicol.

[Figure 2: X-ray diffraction patterns for the AM1 in natura sample with and without ethylene glycol.]

amostra AM1 in natura. Verificou-se que a amostra estudada apresentou perda de massa total de aproximadamente $20,19 \%$, relacionada a perdas de águas (livre, adsorvida e coordenada), matéria orgânica, hidroxilas e carbonatos. A partir da análise térmica diferencial observaram-se as seguintes transformações térmicas: pico endotérmico em aproximadamente $135^{\circ} \mathrm{C}$ relacionado à presença de água livre e absorvida; pico endotérmico em aproximadamente $569{ }^{\circ} \mathrm{C}$ relacionado à presença de hidroxila da esmectita e caulinita; pico endotérmico em aproximadamente $776{ }^{\circ} \mathrm{C}$ relacionado à presença do carbonato de magnésio; pico endotérmico em aproximadamente $878{ }^{\circ} \mathrm{C}$ relacionado à presença do carbonato de cálcio; pico exotérmico em aproximadamente $916{ }^{\circ} \mathrm{C}$ relacionado à nucleação da mulita. Comparando esses resultados da argila estudada e da literatura [23-29] verificou-se que argila apresentou comportamento térmico similar às argilas bentoníticas do estado da Paraíba.

Na Tabela I estão apresentados os diâmetros médios, fração argila abaixo de $2 \mu \mathrm{m}$ e D50\% em relação argila in natura e após tratamentos com hidrociclone, segundo as condições prefixadas como variáveis de processo estudadas.

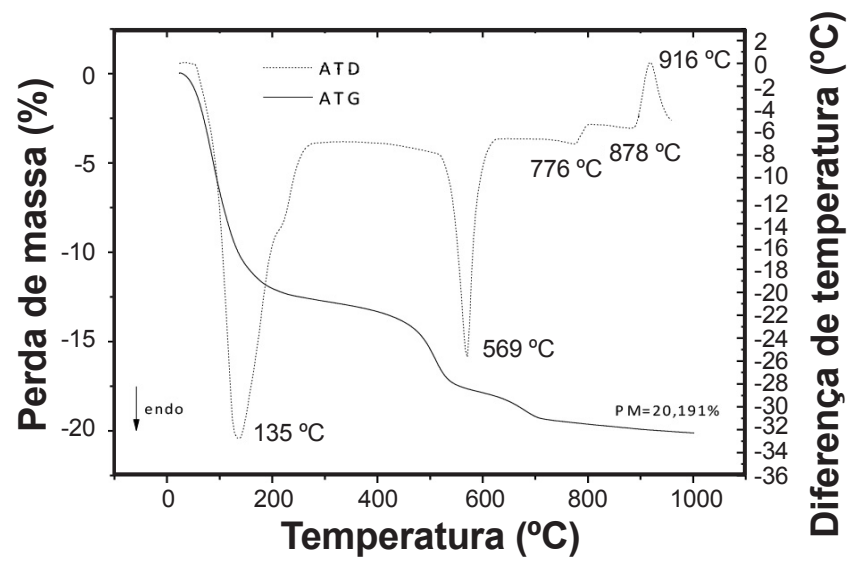

Figura 3: Curvas de ATD e ATG para a amostra AM1 in natura. [Figure 3: TDA and TGA curves for the sample AM1 in natura.] 
Tabela I - Diâmetro médio, fração argila $(\mathrm{D}<2 \mu \mathrm{m})$ e diâmetro a $50 \%$ de massa acumulada em relação às variáveis de processo.

[Table I - Average diameter, clay fraction $(D<2 \mu \mathrm{m})$ and diameter at $50 \%$ of cumulative mass related to the process variables.]

\begin{tabular}{|c|c|c|c|c|c|c|}
\hline Ensaio $\mathrm{N}^{\circ}$ & $\begin{array}{l}\text { Abertura } \\
\text { apex }(\mathrm{mm})\end{array}$ & $\begin{array}{c}\text { Abertura } \\
\text { vortex }(\mathrm{mm})\end{array}$ & Pressão (bar) & $\begin{array}{c}\text { Fração }<2 \mu \mathrm{m} \\
(\%)\end{array}$ & $\begin{array}{l}\text { Diâmetro a } \\
50 \%(\mu \mathrm{m})\end{array}$ & $\begin{array}{l}\text { Diâmetro } \\
\text { médio }(\mu \mathrm{m})\end{array}$ \\
\hline AM1 & - & - & - & 20,89 & 4,45 & 5,21 \\
\hline 1 & 3 & 5,5 & 3,0 & 22,73 & 4,17 & 4,86 \\
\hline 2 & 3 & 5,5 & 3,5 & 23,10 & 4,11 & 4,75 \\
\hline 3 & 3 & 5,5 & 4,0 & 23,92 & 3,92 & 4,50 \\
\hline 4 & 4 & 5,5 & 3,0 & 22,66 & 4,21 & 4,97 \\
\hline 5 & 4 & 5,5 & 3,5 & 22,85 & 4,14 & 4,82 \\
\hline 6 & 4 & 5,5 & 4,0 & 22,58 & 4,17 & 4,84 \\
\hline 7 & 5 & 5,5 & 3,0 & 23,35 & 4,12 & 4,86 \\
\hline 8 & 5 & 5,5 & 3,5 & 23,72 & 4,07 & 4,78 \\
\hline 9 & 5 & 5,5 & 4,0 & 23,80 & 4,01 & 4,68 \\
\hline 10 & 3 & 5,0 & 3,0 & 25,37 & 3,89 & 4,61 \\
\hline 11 & 3 & 5,0 & 3,5 & 25,68 & 3,85 & 4,55 \\
\hline 12 & 3 & 5,0 & 4,0 & 25,40 & 3,88 & 4,58 \\
\hline 13 & 4 & 5,0 & 3,0 & 25,49 & 3,85 & 4,55 \\
\hline 14 & 4 & 5,0 & 3,5 & 24,40 & 3,99 & 4,69 \\
\hline 15 & 4 & 5,0 & 4,0 & 24,87 & 3,93 & 4,61 \\
\hline 16 & 5 & 5,0 & 3,0 & 24,23 & 4,09 & 4,85 \\
\hline 17 & 5 & 5,0 & 3,5 & 24,13 & 4,17 & 5,07 \\
\hline 18 & 5 & 5,0 & 4,0 & 25,62 & 3,93 & 4,65 \\
\hline 19 & 3 & 6,0 & 3,0 & 25,04 & 4,02 & 4,96 \\
\hline 20 & 3 & 6,0 & 3,5 & 25,19 & 3,94 & 4,71 \\
\hline 21 & 3 & 6,0 & 4,0 & 25,56 & 3,90 & 4,68 \\
\hline 22 & 4 & 6,0 & 3,0 & 25,59 & 3,95 & 4,82 \\
\hline 23 & 4 & 6,0 & 3,5 & 26,35 & 3,83 & 4,59 \\
\hline 24 & 4 & 6,0 & 4,0 & 26,13 & 3,91 & 4,70 \\
\hline 25 & 5 & 6,0 & 3,0 & 29,74 & 3,51 & 4,31 \\
\hline 26 & 5 & 6,0 & 3,5 & 30,24 & 3,42 & 4,21 \\
\hline 27 & 5 & 6,0 & 4,0 & 30,21 & 3,44 & 4,24 \\
\hline
\end{tabular}

Observou-se que a argila in natura apresentou diâmetro abaixo de $2 \mu \mathrm{m}$ correspondente a fração argila de $20,89 \%$, diâmetro médio de partículas de 5,21 $\mu \mathrm{m}$ e D50\% de 4,45 $\mu \mathrm{m}$. Esses valores foram similares aos encontrados nos estudos sobre argilas bentoníticas [7, 8]. Em relação às variáveis de processo (Tabela I), verificou-se através da distribuição de tamanho de partículas da argila in natura em relação ao tratamento com o hidrociclone um aumento máximo do concentrado da fração argila $(\mathrm{D}<2 \mu \mathrm{m})$ que correspondeu a um rendimento de $44,7 \%$ para configuração do hidrociclone de apex de $5 \mathrm{~mm}$, vortex de $6,0 \mathrm{~mm}$ e pressão de 3,5 bar. Em relação ao diâmetro médio equivalente das partículas verificou-se redução de aproximadamente 19,2\% para mesma configuração. Para a massa acumulada D50\% observou-se redução de $23 \%$ para mesma configuração. De maneira geral pôde-se concluir que o aumento da pressão e a diminuição nas aberturas apex e vortex tiveram influência marcante no processo de hidrociclonagem em relação à diminuição do tamanho de partículas e aumento do concentrado da fração argila, fato este que pode contribuir em muito para o uso dessa argila para novas aplicações industriais. Nos estudos desenvolvidos em $[9,22]$ sobre uso do hidrociclone, verificou-se que para baixa pressão, ou seja, inferior a 3,0 bar, os valores do concentrado da fração argila foram inferiores aos obtidos nesta pesquisa.

$\mathrm{Na}$ Tabela II estão apresentadas as composições químicas da argila in natura e das amostras após tratamento em hidrociclone. Pôde-se observar que a amostra analisada apresentou elevado teor de $\mathrm{SiO}_{2}(54,6 \%)$ referente à sílica presente na folha tetraédrica do argilomineral como também dos minerais acessórios sílica livre, mica e feldspato. $\mathrm{O}$ valor 
Tabela II - Composição química da argila estudada com e sem tratamento por hidrociclone. [Table II - Chemical composition of clay studied with and without hydrocyclone treatment.]

\begin{tabular}{|c|c|c|c|c|c|c|c|c|c|c|}
\hline Ensaio & $\begin{array}{c}\text { Abertura } \\
\text { apex }(\mathrm{mm})\end{array}$ & $\begin{array}{c}\text { Abertura } \\
\text { vortex }(\mathrm{mm})\end{array}$ & $\begin{array}{c}\text { Pressão } \\
\text { (bar) }\end{array}$ & $\mathrm{SiO}_{2}$ & $\mathrm{Al}_{2} \mathrm{O}_{3}$ & $\mathrm{Fe}_{2} \mathrm{O}_{3}$ & $\mathrm{MgO}$ & $\mathrm{CaO}$ & $\begin{array}{l}\text { Outros } \\
\text { óxidos }\end{array}$ & $\mathrm{PF}$ \\
\hline $\begin{array}{l}\text { Sem hidro- } \\
\text { ciclonagem }\end{array}$ & - & - & - & 54,6 & 21,3 & 6,9 & 3,3 & 2,6 & 2,3 & 8,9 \\
\hline 1 & 3 & 5,5 & 3,0 & 49,7 & 25,0 & 6,8 & 2,0 & 0,9 & 2,4 & 12,4 \\
\hline 2 & 3 & 5,5 & 3,5 & 51,5 & 26,1 & 6,0 & 2,1 & 0,8 & 1,7 & 11,5 \\
\hline 3 & 3 & 5,5 & 4,0 & 51,0 & 25,9 & 5,9 & 2,1 & 0,8 & 1,8 & 12,5 \\
\hline 4 & 4 & 5,5 & 3,0 & 50,0 & 25,5 & 5,5 & 2,9 & 0,7 & 2,3 & 13,0 \\
\hline 5 & 4 & 5,5 & 3,5 & 49,9 & 25,3 & 6,7 & 2,1 & 1,0 & 2,2 & 12,4 \\
\hline 6 & 4 & 5,5 & 4,0 & 50,0 & 25,3 & 7,0 & 2,0 & 1,0 & 2,2 & 12,4 \\
\hline 7 & 5 & 5,5 & 3,0 & 49,9 & 25,6 & 6,4 & 1,9 & 0,7 & 2,2 & 13,0 \\
\hline 8 & 5 & 5,5 & 3,5 & 50,4 & 25,7 & 7,3 & 2,0 & 0,8 & 1,6 & 12,1 \\
\hline 9 & 5 & 5,5 & 4,0 & 50,9 & 25,7 & 6,5 & 2,0 & 0,9 & 2,2 & 11,7 \\
\hline 10 & 3 & 5,0 & 3,0 & 49,5 & 24,7 & 8,1 & 1,9 & 0,9 & 3,5 & 11,7 \\
\hline 11 & 3 & 5,0 & 3,5 & 50,4 & 25,4 & 6,2 & 2,0 & 0,9 & 2,3 & 12,5 \\
\hline 12 & 3 & 5,0 & 4,0 & 51,1 & 25,6 & 5,5 & 2,0 & 1,0 & 2,2 & 12,5 \\
\hline 13 & 4 & 5,0 & 3,0 & 49,6 & 25,3 & 6,3 & 2,0 & 0,7 & 2,4 & 12,9 \\
\hline 14 & 4 & 5,0 & 3,5 & 49,5 & 25,1 & 7,0 & 2,0 & 0,9 & 2,3 & 12,5 \\
\hline 15 & 4 & 5,0 & 4,0 & 50,9 & 25,7 & 5,4 & 2,2 & 0,8 & 2,2 & 12,9 \\
\hline 16 & 5 & 5,0 & 3,0 & 50,1 & 25,3 & 5,9 & 1,9 & 0,9 & 2,3 & 13,1 \\
\hline 17 & 5 & 5,0 & 3,5 & 49,7 & 25,3 & 7,0 & 2,0 & 0,9 & 2,4 & 12,7 \\
\hline 18 & 5 & 5,0 & 4,0 & 49,8 & 25,2 & 6,9 & 1,9 & 0,9 & 3,3 & 12,4 \\
\hline 19 & 3 & 6,0 & 3,0 & 51,2 & 25,6 & 5,7 & 2,2 & 1,0 & 1,9 & 12,0 \\
\hline 20 & 3 & 6,0 & 3,5 & 49,0 & 23,9 & 7,9 & 1,8 & 1,3 & 3,6 & 12,3 \\
\hline 21 & 3 & 6,0 & 4,0 & 50,0 & 25,4 & 6,3 & 2,1 & 0,9 & 2,7 & 12,1 \\
\hline 22 & 4 & 6,0 & 3,0 & 50,1 & 24,6 & 7,5 & 2,0 & 1,1 & 1,5 & 12,7 \\
\hline 23 & 4 & 6,0 & 3,5 & 49,8 & 25,2 & 7,0 & 2,0 & 1,0 & 2,3 & 13,1 \\
\hline 24 & 4 & 6,0 & 4,0 & 50,7 & 25,6 & 6,0 & 2,1 & 1,0 & 2,3 & 12,3 \\
\hline 25 & 5 & 6,0 & 3,0 & 50,6 & 25,7 & 6,2 & 2,1 & 0,9 & 2,2 & 12,6 \\
\hline 26 & 5 & 6,0 & 3,5 & 51,5 & 25,9 & 6,0 & 2,1 & 0,9 & 1,6 & 12,7 \\
\hline 27 & 5 & 6,0 & 4,0 & 51,2 & 25,9 & 5,5 & 2,2 & 0,8 & 2,1 & 12,3 \\
\hline
\end{tabular}

PF - perda ao fogo.

de $\mathrm{Al}_{2} \mathrm{O}_{3}(21,3 \%)$ define a alumina presente nas camadas tetraédricas provenientes da substituição isomórfica bem como da camada octaédrica e dos minerais acessórios mica e feldspato. Observou-se também a presença de $\mathrm{MgO}(3,3 \%)$ e $\mathrm{CaO}(2,6 \%)$ oriundos do carbonato de cálcio (calcita) e da dolomita. O teor de $\mathrm{Fe}_{2} \mathrm{O}_{3}(6,93 \%)$ proveniente da camada tetraédrica da esmectita como também de minerais acessórios, como provavelmente goetita e ilmenita, de acordo com [30]. Esses valores foram de acordo com sua composição mineralógica por DRX (Fig. 2) e ATD (Fig. $3)$. Os valores encontrados foram típicos das argilas do estado da Paraíba, provenientes do reticulado cristalino e acessórios dos argilominerais do grupo da esmectita, sendo semelhantes a resultados encontrados na literatura $[25,31]$.
Em relação às variáveis de processo estudadas neste trabalho (Tabela II), observou-se após tratamento em hidrociclone que o aumento da pressão e a diminuição nos diâmetros do apex e vortex tiveram influência na redução dos teores de impurezas, sendo esses valores ótimos de: $10,6 \%$ para sílica $\left(\mathrm{SiO}_{2}\right)$ oriundo da sílica livre, para pressão de 3,5 bar, abertura apex de 3,0 $\mathrm{mm}$ e vortex de $6,0 \mathrm{~mm}$; aumento de $22,5 \%$ de $\mathrm{Al}_{2} \mathrm{O}_{3}$ corresponde ao aumento relativo à fração argila para configuração com a pressão de 3,5 bar, abertura apex de 3,0 $\mathrm{mm}$ e vortex de $5,5 \mathrm{~mm}$. Para os minerais com ferro $\left(\mathrm{Fe}_{2} \mathrm{O}_{3}\right)$ redução com valor ótimo de $21,7 \%$ para configuração para pressão de 4,0 bar, abertura apex de 4,0 $\mathrm{mm}$ e vortex de 5,0 $\mathrm{mm}$. Para calcita $\left(\mathrm{CaCO}_{3}\right)$ teve-se valor ótimo de $73 \%$ que correspondeu à 
configuração para pressão de 3,0 bar, abertura apex de 4,0 $\mathrm{mm}$ e vortex de $5,5 \mathrm{~mm}$, e para dolomita $\left(\mathrm{MgCO}_{3}\right)$ teve-se valor ótimo de $45,4 \%$ para configuração correspondente à pressão de 3,5 bar, abertura apex de 3,0 mm e vortex de 6,0 $\mathrm{mm}$. Estudos realizados em [9] evidenciaram as diferenças existentes entre as frações finas e grossas separadas por hidrociclonagem, observando-se marcante redução de sílica na fração fina e o consequente aumento do teor de alumina indicando uma nítida concentração da fração argilosa com consequente eliminação dos minerais acessórios presentes. Em resumo, pôde-se concluir que a partir dos valores da composição química que a configuração do hidrociclone (pressão, apex e vortex) pode variar dependendo do mineral acessório a ser retirado. Outro fato que mereceu destaque foi o aumento do concentrado da fração argila em relação à redução nos teores de minerais acessórios evidenciando a importância das variáveis de processo do hidrociclone no beneficiamento de argilas esmectitícas para uso industrial. Comparando com dados da literatura $[9,22]$ para pressão constante do hidrociclone, os resultados foram superiores.

Quanto aos resultados dos difratogramas de raios X foi apresentado unicamente aquele referente ao melhor valor obtido para concentração ótima da fração argila, que se constituiu como objetivo primordial deste trabalho. Os resultados completos podem ser encontrados em [32]. A Fig. 4 ilustra o difratograma da amostra AM1 após processo de hidrociclonagem para a configuração ótima da fração argila $(\mathrm{D}<2 \mu \mathrm{m}$ ): apex de $5 \mathrm{~mm}$, vortex de $6 \mathrm{~mm}$ e pressão de 3,5 bar. Observou-se a presença do argilomineral do grupo da esmectita (JCPDS 29-1497), caracterizado pelas distâncias interplanares de aproximadamente 12,9 e 4,7 $\AA$. Observouse também a presença do argilomineral caulinítico (JCPDS 14-0164), caracterizado pelas distâncias interplanares de 7,21 e $3,57 \AA$. Percebeu-se que ocorreu pequeno aumento da intensidade dos picos característicos do argilomineral esmectítico, indicando que ocorreu aumento do teor do argilomineral. A presença de quartzo (JCPDS 46-1045)

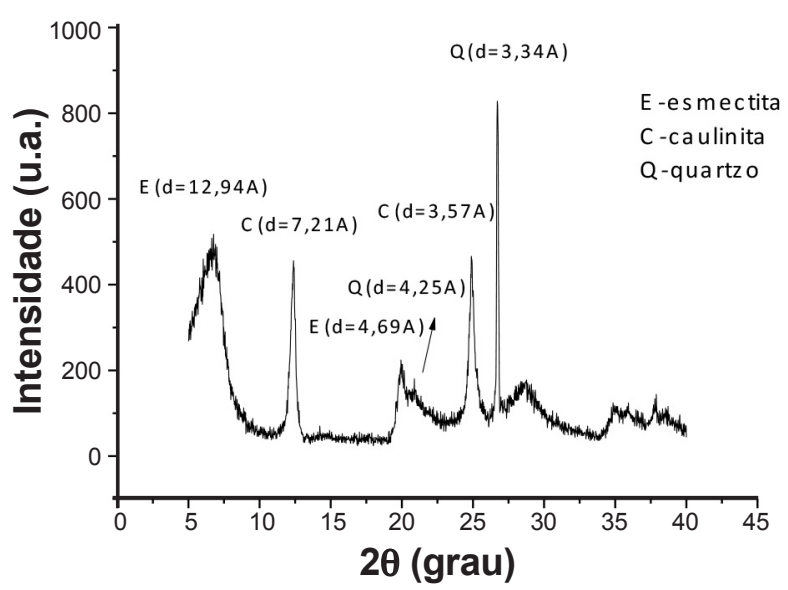

Figura 4: Difratograma de raios X para configuração apex $5 \mathrm{~mm}$, vortex $6 \mathrm{~mm}$ e pressão 3,5 bar.

[Figure 4: X-ray diffraction pattern for configuration apex $5 \mathrm{~mm}$, vortex $6 \mathrm{~mm}$ and pressure $3.5 \mathrm{bar}$.] foi caracterizada pelas distâncias de 4,25 e 3,34 Å. Foi perceptível que ocorreu maior redução da intensidade do pico característico do quartzo, quando comparado com a Fig. 1 , resultado que foi de acordo com os valores encontrados na composição química (Tabela II). Esses dados confirmaram a eficiência da hidrociclonagem no processo de tratamento de argilas esmectitícas. Esses resultados foram superiores aos encontrados em $[14,22]$ para pressões inferiores a 3,0 bar

\section{CONCLUSÕES}

Com o objetivo de estudar a influência das variáveis envolvidas no processo de hidrociclonagem para tratamento de argilas bentoníticas foi possível concluir que para o ponto ótimo houve uma redução do diâmetro médio equivalente das partículas de aproximadamente $19,2 \%$, e um rendimento da fração argila $(\mathrm{D}<2 \mu \mathrm{m})$ de $44,7 \%$ para configuração do hidrociclone de abertura de apex de $5 \mathrm{~mm}$, abertura de vortex de 6,0 mm e pressão de 3,5 bar. Quando se considerou a composição química da amostra in natura em relação à tratada em hidrociclone, observou-se diminuição considerável na quantificação do óxido de silício $(10,6 \%)$, ferro $(21,7 \%)$, calcita $(73,0 \%)$ e dolomita $(45,3 \%)$ para diferentes configurações, incluindo pressão e aberturas do apex e vortex. Outro fator importante observado foi que o aumento da pressão e a diminuição nos diâmetros do apex e vortex tiveram influência significativa no processo de hidrociclonagem em relação a cada tipo de mineral acessório presente nas argilas, fato este que pode contribuir em muito para o uso dessas argilas para aplicações industriais.

\section{REFERÊNCIAS}

[1] R.R. Menezes, L.R.L. Melo, F.A.S. Fonseca, H.S. Ferreira, A.B. Martins, G.A. Neves, Rev. Eletr. Mater. Proc. 3, 2 (2008) 36-43.

[2] R. Barbosa, D.D.S. Morais, E.M. Araujo, T.J.A. Melo, Cerâmica 58, 347 (2012) 25-34.

[3] M.I. Abdou, A.M. Al-Sabagh, M.M. Dardir, Egypt. J. Petrol. 22 (2013) 53-59.

[4] L.B. Paiva, A.R. Morales, F.R.V. Díaz, Appl. Clay Sci. 35 (2007) 45-52.

[5] A.R.V. Silva, H.C. Ferreira, Rev. Eletr. Mater. Proc. 3, 2 (2008) 26-35.

[6] H.S. Ferreira, R.R. Menezes, A. B. Martins, G. A. Neves, H.C. Ferreira, Cerâmica 54, 329 (2008) 77-85.

[7] I.D.S. Pereira, V.N.F. Lisboa, I.A. Silva, J.M.R. Figueirêdo, G.A. Neves, R.R. Menezes, Mater. Sci. Forum 798-799 (2014) 50-54.

[8] I.A. Silva, I.D.S. Pereira, W.S. Cavalcante, F.K.A. Sousa, G.A. Neves, H.C. Ferreira, Mater. Sci. Forum 820 (2015) 68-75.

[9] J.M.R. Figueirêdo, J.M.Cartaxo, I.A. Silva, C.D. Silva, G.A. Neves, H.C. Ferreira, Mater. Sci. Forum 805 (2015) 486-491.

[10] F.J. Souza, L.G.M. Vieira, J.J.R. Damasceno, M.A.S. Barrozo, Powder Technol., 107 (2000) 259-267. 
[11] E.A. Barbosa, L.G.M. Vieira, C.A.K. Almeida, J.J.R. Damasceno, M.A.S. Barrozo, Mater. Sci. Forum 416 (2003) 317-322.

[12] D.R. Mailapalli, P.A.A. Marques, K.J. Thomas, Rev. Eng. Agríc. 27, 2 (2007) 373-382.

[13] A.B. Martins, "Uso de um hidrociclone para purificação de esmectitas", Diss. Mestr., Un. Fed. Campina Grande (2009) 107.

[14] F. Boylu, K. Çinku, F. Esenli, M.S. Çelik, Int. J. Miner. Process. 94 (2010) 196-202.

[15] O. Cruz, J.R. Zanini, A.C. Barreto, A.S. Ferraudo, Rev. Bras. Agric. Irrigada 5, 4 (2011) 254-264.

[16] M.G. Farghaly, V. Golyk, G.A. Ibrahim, M.M. Ahmed, T. Neesse, Miner. Eng. 23 (2010) 321-325.

[17] V. Golyk, S. Huber, M.G. Farghaly, G. Prolss, E. Endres, T. Neesse, M.A. Hararah, Miner. Eng. 24 (2011) 98-101.

[18] A. Davailles, E. Climent, F. Bourgeois, Sep. Purif. Technol. 92 (2012) 152-160.

[19] I.A. Silva, J.M.R. Costa, H.S. Ferreira, R.R. Menezes, G.A. Neves, H.C. Ferreira, Cerâmica 58, 347 (2012) 317327.

[20] J.M.R. Figueirêdo, J.P. Araújo, I.A. Silva, J.M. Cartaxo, G.A. Neves, H.C. Ferreira, Mater. Sci. Forum 798-799 (2015) 21-26.

[21] P.L. Oliveira, J.M.R. Figueirêdo, J.M. Cartaxo, G.A. Neves, H.C. Ferreira, Mater. Sci. Forum 798-799 (2014) 5560.

[22] V.C. Marques, H.C. Silva, A.M.T. Rodrigues, J.M. Cartaxo, R.R. Menezes, H.S Ferreira, Cerâmica 61, 359
(2015) 285-297.

[23] L.V. Amorim, C.M. Gomes, H.L. Lira, K.B. França, H.C. Ferreira, Mater. Res. 7, 4 (2004) 585-593.

[24] L.F.A. Campos, L.V. Amorim, H.C. Ferreira, Cerâmica 53, 325 (2007) 68-73.

[25] H.S. Ferreira, L.F.A. Campo, R.R. Menezes, J.M. Cartaxo, L.N.L. Santana, G.A. Neves, H.C. Ferreira, Cerâmica 59, 350 (2013) 277-284.

[26] F.K.A. Sousa, A.P. Ramos, L.F.A. Campos, R.R. Menezes, H.S. Ferreira, G.A. Neves, Cerâmica 57, 342 (2011) 199-205.

[27] D.A. Tonnesen, L.C. Bertolino, A.B. Luz, F.T. Silva, D.M.O. Timóteo, Holos 1 (2012) 15-20.

[28] A.P.S. Batista, R.R. Menezes, L.N. Marques, L.A. Campos, G.A. Neves, H.C. Ferreira, Rev. Eletr. Mater. Proc. 4, 3 (2009) 64-71.

[29] R.R. Menezes, P.M. Souto, L.N.L. Santana, G.A. Neves, R.H.G.A. Kiminami, H.C. Ferreira, Cerâmica 55, 334 (2009) 163-170.

[30] P. Souza Santos, Ciência e tecnologia de argilas, $2^{\text {a }}$ Ed., Vol. 1, Edgard Blücher, S. Paulo (1989).

[31] M.M. Carrera, A.F.D.C. Varaião, M.A. Gonçalves, Rev. Escola Minas 61, 1 (2008) 97-105.

[32] A.J.A. Gama, "Modelagem, simulação e otimização do processo de hidrociclonagem para tratamento de argilas bentoníticas", Tese Dr., Un. Fed. Campina Grande (2016) 127.

(Rec. 18/07/2016, Rev. 22/09/2016, 14/10/2016, Ac. 17/12/2016) 